\title{
Sex Work and Social Media: \\ Online Advocacy Strategies
}

\author{
Emma E. Duke \\ ees111@mun.ca \\ Kathleen C. Sitter \\ University of Calgary \\ Nicole Boggan
}

\begin{abstract}
Online communication continues to provide opportunities to connect, mobilize and disseminate information amongst direct service organizations. While the use of social media among nonprofits continues to expand, there is a paucity of research that documents the extent to which online channels - particularly social media - are adopted and used amongst organizations that support sex workers. Online advocacy efforts have grown over the last decade, with sex workers and non-profit organizations at the forefront. This article evaluates the presence and social media strategies amongst organizations providing direct services for sex workers in Canada. Eightyseven organizations operating in Canada were examined to assess both the types of social media channels used, and the online strategies employed. Results indicate there is a propensity for agencies to engage in multiple social media platforms with spaces for service users to post information in lieu of static sites that predominantly support one-way communication. Recommendations and best practices include integrating postings across platforms for efficiency, developing and maintaining safe spaces online, and focusing on channels that support multilogue communication.
\end{abstract}

Keywords: Sex work, social media, knowledge

As the use of social media advocacy among non-profits expands, how it is being used by service organizations that support sex workers is still largely unknown. This article describes the online presence and social media strategies amongst organizations providing direct services for sex workers in Canada. Eighty-seven organizations operating in Canada were examined to assess both the types of social media channels used, and the online strategies employed. These organizations provide direct services for adult sex workers. Findings indicate there is a propensity for agencies to engage in multiple social media platforms with spaces for service users to post information in lieu of static sites that predominantly support one-way communication. Recommendations and best practices include integrating postings across platforms for efficiency, developing and maintaining safe spaces online, and focusing on channels that support multilogue communication. Implications related to best practices amongst organizations that provide direct services to communities and online advocacy are also discussed. 


\section{Sex Work and Direct Services: Underlying Ideologies}

Sex workers often represent one of the more marginalized and stigmatized groups in Canada. In this article, the term "sex work" refers to adults over 18 years of age who engage in a range of activities where sexual services are exchanged for money or other goods (Capous Desyllas, 2013). Accessing supports present numerous challenges for sex workers, as the ideological stance of organizations often inform the types of direct services and programming available. For instance, Oselin and Weitzer (2013) examined the type of services provided to sex workers in North America, and categorized programming in terms of ideological stances pertaining to sex work. Three dominant perspectives were noted: radical, rights-based, and polymorphous. A radical perspective posits all types of sex work as exploitative. In the Canadian judicial system, the radical perspective is evident in the 2014 passing of the Protection of Communities and Exploited Persons Act. Commonly referred to as the Nordic model, this legislation positions sex work as a form of sexual exploitation where clients are criminalized.

In contrast, a rights-based perspective holds a 'sex-work-is-work' positionality. The third position, polymorphous, also considers the different structural and judicial contexts as well as the lived experiences of a person's life. This perspective holds intersectionality at the core, and recognizes that lived experiences vary across a continuum (Oselin \& Weitzer, 2013). We posit that the polymorphous perspective also closely aligns with a rights-based approach.

Over the last 40 years there has been an emergence of rights-based Canadian organizations providing direct services for adult sex workers. The first established rights-based group was formed in 1977, and was referred to as 'Better End All Vicious Erotic Repression' (BEAVER), later renamed 'Coalition Against Street Harassment' (CASH) (Cockerline et al., 1995). CASH focused on social and political citizenship, violence faced by sex workers and Canadian laws. The Canadian Organization for the Rights of Prostitutes (CORP) was created to fight against the criminalization of communicating for the purposes of selling sexual services (Cockerline et al., 1995).

A rights-based approach views sex work as a choice, and recognizes that choices are influenced by "power structures of race, class, sexuality and gender, [however] these structures are neither inevitable nor unchanging" (Jeffrey \& MacDonald, 2006, p. 10). With that in mind, organized political groups recognized "a serious lack of relevant and appropriate services" for sex workers (Beer, 2011, p. 62). Subsequently, organizations by and/or sex workers began to develop and take shape across Canada to focus primarily on addressing the immediate needs of sex workers (Beer, 2011). Jackson (2016) notes that among sex workers, a rights-based approach is "rooted in an activist ideology of worker rights within (and challenging) a neoliberal economic structure" (p. 28). Jackson (2016) further states that the rights-based movement has long countered protectionist politics; the rights-based approach has largely been in response to the victim narrative that has failed to improve conditions for sex workers and anti-trafficking initiatives that tend to conflate sex work with trafficking. 


\section{Direct Services and Social Media: Digital Literacy and Knowledge Production}

Social media platforms have expanded over the last decade, creating new forums to share, create, and express knowledge. Within the sex worker rights movement, social media has become a change-maker in terms of how information is produced and used. Social media has been instrumental amongst Canadian sex workers in accessing information and resources (Arthur, 2013; Keep, 2015). Online communication for organizations providing direct services for sex workers has been central for outreach, particularly with information sharing and engagement. As Beer notes:

Websites and online discussion forums dedicated to the movement and conversations about sex worker rights reveals a larger and diverse body of supporters...the internet can increase movement consciousness, and participation among sex workers who wish to remain anonymous, who face scheduling or time constraints, live in remote areas and feel otherwise isolated from a sex worker community (2011, p. 72).

A number of Canadian sex-worker run organizations like Sex Professionals of Canada (SPOC), Maggie's in Toronto, and Peers in Victoria have social media accounts on Twitter and Facebook. They provide vital services for sex workers, while challenging the stigma and criminalized status associated with sex work (Bedard, 2015). In Newfoundland and Labrador, Safe Harbour Outreach Project (SHOP), regularly uses its social media accounts to share alarms of sexual assaults through their Warn Other Workers (WOW) Line, promote social justice and engage in political activism for sex work rights. Similarly, Stepping Stone in Nova Scotia seeks to "move beyond moralistic politics and try to negotiate a more nuanced and complex response to sex work based on sex workers' own experiences" (MacDonald, Jeffrey, Martin, \& Ross, 2013, p. 165).

Online presence. While organizations that provide direct services for sex workers use social media, our knowledge of the online presence and strategies of how social media channels are used is limited. There is also a recent call amongst scholars in the field of sex work for the need to understand the role of social media amongst organizations that provide direct services to sex workers (Beer, 2011; Capous Desyllas, 2013; Oselin \& Weitzer, 2013). As noted by Beer, "we have yet to measure the process and impact of online consciousness-raising, and coalition building, but technology has certainly impacted and perhaps expanded the movement, putting people in contact with one another in ways that were not possible before" $(2011$, p. 91). To address this need, the presence and social media strategies of Canadian organizations that provide direct services for sex workers are examined.

\section{Method}

To understand the social media presence and strategies amongst Canadian organizations providing direct services to adults involved in sex work, an analysis of online platforms was conducted. Criteria was restricted to organizations operating in Canada that provided some form of direct service to sex workers. Specifically, sample criteria included Canadian organizations that: (1) provide direct or indirect services, resources and information to sex workers, (2) operate in Canada, with a mandate or mission to provide services in Canada, and (3) have an online media presence. We compiled a list of all organizations across Canada that met this criterion. 
Organizations serving youth-only were excluded from the sample ${ }^{1}$. Inclusion criteria included organizations with various ideological perspectives, including radical, rights-based, and polymorphous. In targeting the largest scope of potential organizations possible, both online and offline searches were conducted. Online Web searches of key words included 'sex work organizations', 'sex work outreach', and 'prostitution,' which also identified organizational websites. A secondary snowball sampling involved searching organizations that followed/liked other Canadian agencies via social media networks.

Based on these criteria and at the time of data gathering of online platforms, a total of 87 organizations were found to support current, former, and exiting sex workers, inclusive of all genders, Trans*, racialized, and Indigenous peoples. Organizations and agencies were categorized based on whether they were an umbrella organization that offered a program or service within their overall portfolio, or if they were a dedicated stand-alone agency with a mandate focused on supporting sex workers. We then examined the social media platforms and online presence of each organization.

The data set was deductively analyzed and guided by Guo and Saxton's (2014) social media framework utility of social service organizations and Megele's (2014) construct of social media usage. Data was coded based on platform type, reciprocal flow/feedback loops, level of activity, and integration across platforms. We coded these variables, particularly noting the online presence of the social media platforms adopted by the organizations. Figure 1 highlights the percentage of these social service agencies using social media technologies, and the types of platforms that are used.

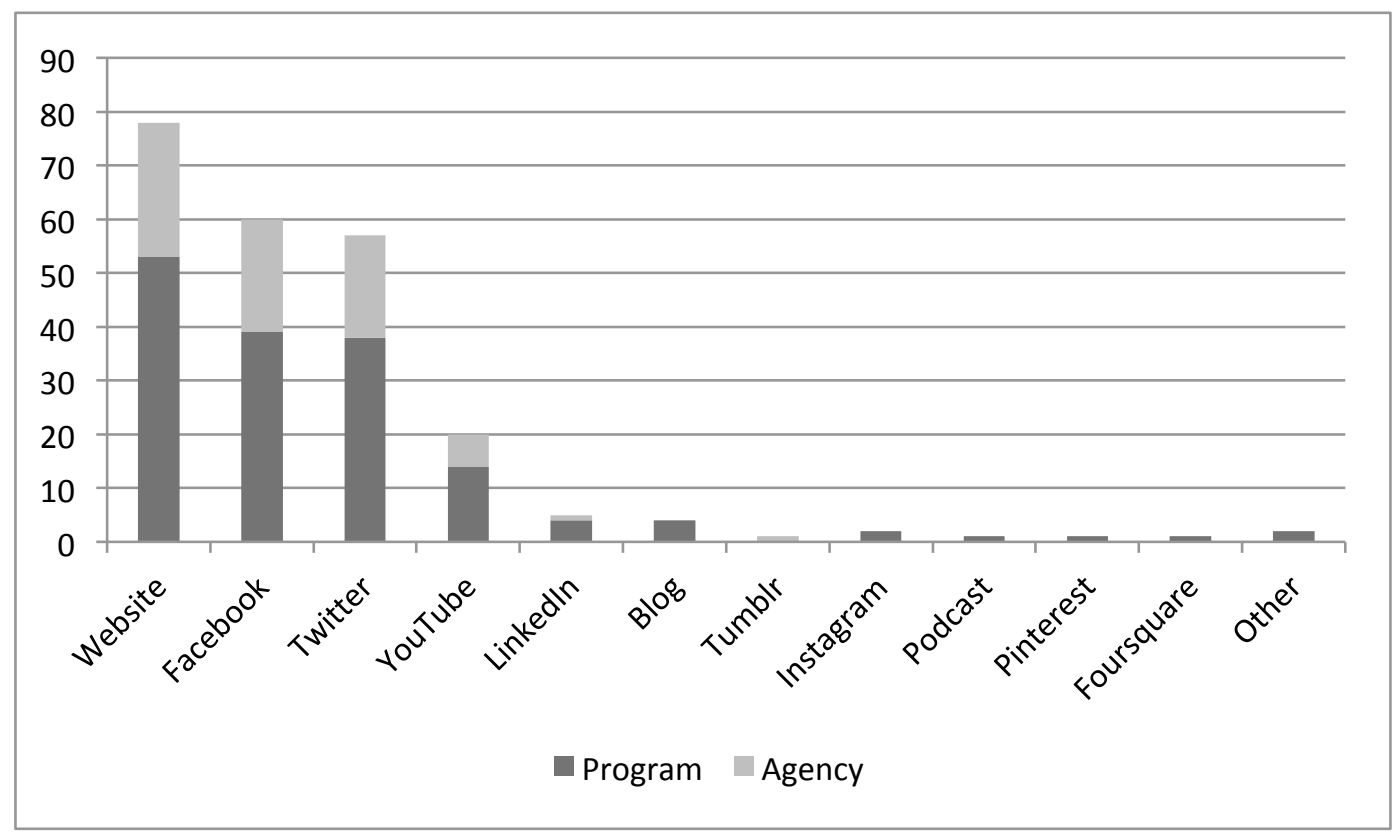

Figure 1: Canadian Social Service Agencies Providing Direct Services to Sex Workers Using Social Media

\footnotetext{
${ }^{1}$ Youth-only groups were excluded to differentiate between sexual exploitation of youth and sex work.

Cultural and Pedagogical Inquiry, Summer 2018, 10(1), pp. 49-61

ISSN 1916-3460 (C) 2018 University of Alberta

http://ejournals.library.ualberta.ca/index.php/cpi/index
} 
These organizations were examined to assess both the types of social media channels used and the online strategies employed.

\section{Findings}

Findings indicate there is a propensity for agencies to engage in multiple social media platforms. Findings are examined through three emerging themes: Landing pages, integrated platforms, and multilogue sites.

\section{Landing Pages}

Agencies predominantly use social media sites in conjunction with a static website platform, where the websites act at the key landing page for overall information about the services and programs. Websites were also the major focal point linking all social media platforms. While social media is also often used to convey information, websites appear to be the dominant platform in which the bulk of substantial information is posted. At times, websites also have active pages that include posts and updated information (e.g. blogs or calendars of events).

Umbrella organizations that have a broader mandate often presented with updated websites that also held separate webpages and/or blogs for programs supporting sex workers. For example, the Safe Harbour Outreach Project (SHOP) is a program within the St. John's Status of Women Council. The St. John's Status of Women Council promotes information about SHOP on their website and social media accounts, in addition to dedicating a separate page specifically about information relevant to SHOP and people accessing their services.

\section{Platform Integration}

Platform integration refers to online sites with active links that direct viewers to their other social media sites. For instance, an organization's webpage that has an active link to their Twitter and Facebook accounts would be a form of platform integration+ Four characteristics of platform integration were found in the data set: 1) pure matches, 2) partial integration, 3) no integration across platforms, and 4) other/unknown. Pure matches included organizations that had links to all their social media on each of their respective platforms. Partial integration included organizations that had only a sub-set of social media included. For example, an organization might have links to all their social media accounts, but these accounts only had a link to the websites, and no other platform. For this to be a pure match, in this scenario, Twitter and Facebook would have links to all the organization's platforms. No integration indicated there were no links shared across any online platforms, and unknown/other included broken links. The following tables further highlight the level of integration of these platforms. 


\begin{tabular}{|l|l|l|l|}
\hline Online Platforms & Program & Agency & Total \\
\hline $5+$ & 1 & 6 & 7 \\
\hline 4 & 5 & 10 & 15 \\
\hline 3 & 11 & 16 & 27 \\
\hline 2 & 5 & 11 & 16 \\
\hline $1 *$ & 5 & 16 & 21 \\
\hline 0 & 0 & 1 & 1 \\
\hline Total & 27 & 60 & 87 \\
\hline
\end{tabular}

Figure 2: Online Platforms

\begin{tabular}{|l|l|l|}
\hline *Website/webpage Only Online Platform \\
\hline Program & Agency & Total \\
\hline 4 & 12 & 16 \\
\hline
\end{tabular}

Figure 3: Website/webpage only platforms

\begin{tabular}{|l|l|l|l|}
\hline Integration & Program & Agency & Total \\
\hline Pure Integration & 5 & 1 & 6 \\
\hline Partial Integration & 37 & 18 & 55 \\
\hline Single Platform & 15 & 4 & 19 \\
\hline None & 1 & 0 & 1 \\
\hline Inactive/Broken Links & 2 & 4 & 6 \\
\hline Total & 60 & 27 & 87 \\
\hline
\end{tabular}

Figure 4: Level of Integration Across Platforms

Pure matches only occurred within organizations that had only two social media platforms. These bi-directional links were predominantly with a website + one other site (either Facebook or Twitter). While websites continue to be the dominant platform, only 14 agencies solely had websites; most organizations had at least one other social media platform. There were only three organizations without websites and they used Facebook or Twitter. Only three organizations solely had Twitter, and 10 with only Facebook. A number of non-profits did not integrate their social media accounts together, making them less accessible to online viewers. Moreover, a number of organizational websites provided no social media links at all. This has potential limitations for sharing information to audiences using different platforms, if agencies do not post consistent information across their online sites.

However, most platforms appeared only partially integrated, where websites had limited up-to-date information. Outside of the pure matches, there failed to be reciprocity across platforms. At the time of data gathering, the dominant platforms - Twitter and Facebook - had a specific space for a website link. However, agencies could include active links within the description section to develop "pure matches" across platforms. Examples of organizations with social media that was partially integrated include Big Susie's in Hamilton, SHIFT in Calgary, Pace Society in Vancouver, CATIE, and YWCA in Yellowknife.

While on the surface, organizations that have purely integrated platforms appear to be using social media most optimally, the level of integration of social media platforms does not 
necessarily reflect the diversity of the organization's platforms, or how well they are reaching their communities. For example, STORM in Ottawa and SWAN in Vancouver had a Facebook account which linked back to their respective websites and vice versa, but lacked a Twitter account at the time of data collection.

Pure integration was not indicative of a strong social media presence. For example, Stepping Stone in Nova Scotia was found to have partial integration, but they have a specific section of their website dedicated to social media, complete with a Facebook feed that conveys updates in real time and makes it easy for visitors to engage with posts. In addition to this, Stepping Stone's initiative entitled Keystone Konnections aims to bridge connections between diverse sex trade workers, in order to enhance personal power and facilitate mobilization for social and political change. Keystone Konnections uses online spaces and telephone outreach services in order to connect workers and accomplish this goal.

\section{Multilogue Sites}

Agencies predominantly have multiple social media platforms, with spaces for service users to post information in lieu of static sites that mainly support one-way communication. Megele's (2014) research about social media and social work explored the importance of monologue and multilogue online engagement. Multilogue refers to many-to-many online conversations where interactions are more dynamic and open compared to static sights or webpages that only provide one-way information to online viewers.

Findings indicate that organizations that provide direct services for sex workers are actively using social media platforms to mobilize and communicate directly with people accessing services. For instance, live Twitter feeds prompt easy access to real-time updates. Examples of organizations that featured live Twitter feeds on their website include Stella's Circle in St. John's, Dream Catchers in Winnipeg, PEERS in Victoria, and Pivot Legal Society and FIRST, both of the latter organizations are based in Vancouver. Tethering online domains such as having live Twitter feeds on websites holds great potential to reach more people who are accessing services while concomitantly creating efficiencies in time, which is particularly important for non-profits that historically rely on low budgets and limited staff.

Some organizations also featured live Facebook feeds on their website, which similarly updates the websites with Facebook posts in real time and allows viewers to efficiently share information and engage with the organization. For example, Stepping Stone in Halifax and the Migrant Sex Worker's Project in Toronto use Facebook feeds on their websites. HIV North in Alberta and the AIDS Coalition of Nova Scotia use Facebook and Twitter feeds on their website, compounding the efficient use of social media and allowing visitors to connect with both social media platforms.

Several social media pages posted "bad date" lists, or warnings about dangerous clients. Information about drop-in services, outreach, social gatherings and information sessions were primarily communicated through Twitter and Facebook pages as opposed to the main website. In fact, at the time of data gathering, three organizations that provide direct services to sex workers had only social media accounts without websites. The focus of communication largely integrated service delivery and information on protests, rallies and marches targeting sex worker rights and information pertaining to legislation and policy. 
The authors conclude that multilogue sites create the most space for dynamic and farreaching modes of online support and communication for sex workers. Traditionally, organizations have provided support by offering meals, harm reduction, information and resources, assistance with housing, crisis intervention and counseling. By offering multilogue social media platforms, organizations that serve sex workers are empowering sex workers to participate in public dialogue, meaning making and challenging dominant paradigms. Below is a further analysis of how a specific organization effectively uses a multilogue site while serving sex workers. It emphasizes how social media use can be an effective support tool for sex workers.

The application of multilogue sites. The application of multilogue sites not only to provide announcements regarding regular services and current events, but also to increase public engagement among sex workers and sex worker allies in their community and beyond. The following section highlights several examples: mobilization efforts, developing community connections for service-users, building relationships at the national and international levels, and amplifying knowledges and experiences of sex workers.

With consideration to mobilization, SHOP uses Twitter to both promote an event being held by their umbrella organization (St. John's Status of Women Council) and invite sex workers and allies to join them at activist events.

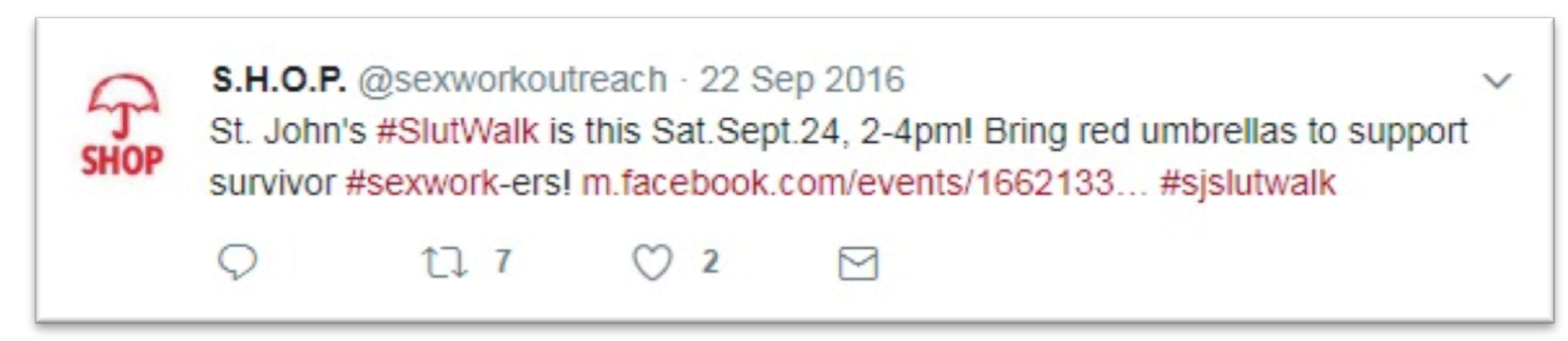

This invitation helps establish a relationship between the organization, sex workers and sex worker allies. Multilogue websites also hold a great deal of promise for organizations to promote and establish relationships among organizations with similar mandates. With this approach, SHOP also helps local sex workers become familiar with other organizations that could be potential resources to them in their own community.

Similarly, the use of multilogue platforms enables organizations to open avenues for collaboration and communication among varying distances. In this example, Twitter is used to establish a relationship with other organizations that serve sex workers across Canada, such as Pace Society.

S.H.O.P. Retweeted

PACE Society @PaceSociety.19 Aug 2016

Media reproduce a lot of myths about \#sexwork that increase the risk of sexual assault for sex workers@femmeifest 
This situates SHOP alongside other Canadian and international organizations that serve similar purposes in their respective communities, but also might expand SHOP's audience to sex workers and sex worker allies. Considering that sex work can be a migratory profession, this may also help both sex workers migrating to and from Newfoundland become connected with other organizations that serve individuals in the sex trade. The approach not only connections within international community, but also as a means to promote ideas, services, and trends and so forth that are compatible with their mandate.

Finally, SHOP uses multilogue platforms to actualize their organizational goals of amplifying the voices of sex workers and centering their experiences. In this example, SHOP retweets a sex worker's perspective on laws which criminalize demand and limit the ways and spaces in which sex workers can work.

โ] S.H.O.P. Retweeted

Let's be clear:

22 Aug 2016

If u crimlz \#sexwork our workplaces or clients u crimlz us

The use of social media platforms, such as Twitter, opens up avenues for organizations to engage with sex workers and expand their audience for their content. The use of multilogue sites offers another means for such as SHOP, to enact their mission to centre sex workers in conversations about issues that impact their lives.

\section{Recommendations}

Social media offers new opportunities for advancing activism (Obar, 2014). Obar's (2014) analysis of Canadian non-profit social media use found that a major barrier is lack of knowledge and education with its use. Understanding how to engage with platforms like, Facebook, Instagram, or Twitter is incremental to advocating for and with sex workers.

Marches and rallies in the street are still a prominent factor in advocacy, however our research revealed that many organizations providing direct services for sex workers are producing blogs, online petitions and Twitter accounts. These platforms create space for sex workers and their allies to mobilize digitally in large numbers. Sex workers engaged in online dialogue also challenges and disrupts the exploited victim rhetoric and reconstructs a more complex identity that validates individual voice.

However, a number of issues can also interfere with social media usage, particularly if it risks unwanted visibility in online spaces. The potential overreliance of social media also raises concerns of excluding sex workers who lack online access (Beer, 2011). Critiques also include social media advocacy perpetuating continued dominance of those already with considerable influence and power (Chalmers \& Shotton, 2015) as well as concerns with safety, trolling, and online assaults, which are the realities faced by many bloggers and online advocates, particularly amongst women. 
These are considerations for any organization when developing online strategies for engagement and advocacy. Based on the level of integration across platforms, there are three main recommendations associated with social media for agencies that provide direct services for sex workers. These three areas focus on efficiency, safety, and enhanced communication.

Efficiency. Many social Canadian service agencies have limited resources. Being able to engage with sex workers in online spaces that transcends into off-line contexts is a delicate balance. Doing this in an efficient way is paramount for the survival and ongoing engagement by agency members. At the minimum, the ability for agency members to post across sites instantaneously is critical. Using a system such as Hootsuite to integrate postings across platforms can save time, while maintaining reach and consistent messaging. While online audiences will continue to respond across social media sites, it affords agency members the initial means to relay congruent information (e.g. bad dates, offline events and meetings, etc.) in real-time. It also does not require only one dominant platform by sex workers.

While websites continue to be the predominant online platform, updating websites is time consuming, particularly among agencies with limited resources. For these agencies and programs, an effective approach can involve maintaining a static website requiring limited maintenance while ensuring integration across media platforms. This approach also affords opportunities with direct service user engagement via other sites.

Safety. When engaging in online communication, safety is an important consideration, particularly when working with people who are often on the margins of society that deal with pervasive stigma and oppression. In our review of the social media platforms used by agencies in this study, we found variances between closed and open forums, particularly with Facebook and Twitter accounts. An agency's mandate or policy may inform the reasons for these differences, especially with consideration to how social media is used with sex workers availing of services and information. For instance, private online groups hold different strengths and concerns for people wishing to access online services. Developing online groups with private membership affords the organizations the ability to maintain the integrity of these spaces to exchange information and feel a sense of community, and security. The downside of these private online spaces is that sex workers who may not be willing or able to join are isolated from discussions that occur in private groups.

However, trolling is a reality of social media that does create unsafe, vulnerable, and dangerous spaces for many people communicating online. This is also very prevalent when the format or platform structures do not lend itself to multilogue. Disabling comments for posts in certain spaces (e.g. YouTube) may be an action worth considering, especially if there are other spaces where online two-way communication is present. Moreover, an option to log-in to an account, like Hustle at HIM provides on their website, is another strategy. Further research in this area with organizations is needed is terms of their experience with safety and social media.

Enhancing Communication. How can non-profits increase their online presence? Online spaces provide a means to communicate directly with people accessing services. However, currently there are certain social media platforms that lend themselves more effectively to two-way communication compared to others. Ensuring an agency has at least one site for multilogue is critical, as it keeps online communication channels open. We recommend that organizations include a hyperlink on their website to all social media accounts, and within 
those social media accounts also ensure handles are shared across platforms to increase reach. These small, yet incremental, connections can have tremendous impact on how social media sites are accessed and used by sex workers. For example, Newfoundland and Labrador's SHOP issued a red alert report about a sexual assault in 2016, a tool to warn sex workers of potentially violent clients (SHOP, 2016). This alert was issued digitally through the Website, Twitter, and Facebook pages, reaching sex workers, service providers and advocates on multiple platforms in real-time.

\section{Implications for Practice}

Non-profits that have an active online-presence can broaden their networks, engage in community activism, participate in the production of knowledge and connect with service users in real-time. Social media as a tool for direct-service organizations, can change the way frontline staff communicate with community members and activists while engaging in activism themselves. Direct service organizations must begin accessing and embracing technologies like social media platforms if they wish to meet the needs of the people they are serving. Sitter and Curnew (2016) claim that "without this focus, there is a risk of digital exclusion... which can inadvertently impact our ability to work effectively" (p. 272).

Sex workers engaged in online dialogue are contributing their own lived experience to an existing body of knowledge. They are interrogating and interrupting existing hegemonic victim rhetoric and challenging dominant discourse. The hope is this research will prompt Canadian non-profits that serve sex workers to analyze how their social media platforms are being utilized and/or underutilized to become more accessible for sex workers. 


\section{References}

Arthur, J. (2013, April 5). The sex workers are coming! Rabble News. Retrieved from: http://rabble.ca/columnists/2013/04/sex-workers-are-coming

Bedard, E. (2015, March 24). For whose protection? On the failures of Canada's new sex work legislation. GUTS Canadian Feminist Magazine. Retrieved from:

http://gutsmagazine.ca/blog/for-whose-protection

Beer, S. (2011). The sex worker rights movement in Canada: Challenging the 'prostitution laws'. Electronic Theses and Dissertations. Paper 500. University of Windsor, Canada.

Capous Desyllas, M. (2013). Representations of sex workers' needs and aspirations: A case for arts-based research. Sexualities, 17(7), 772-787.

Chalmers, A. W. \& Shotton, P. A. (2015). Changing the face of advocacy? Explaining interest organizations' use of social media strategies. Political Communication, 33(3), 374-391.

Cockerline, D., Gwendolyn \& Sorfleet, A. (1995). A brief history of sex worker activism in Toronto. Walnet. Available at:

http://www.walnet.org/csis/groups/swat/torontohistory.html

Guo, C. \& Saxton, G. D. (2014). Tweeting social change: How social media are changing nonprofit advocacy. Nonprofit and Voluntary Sector Quarterly, 43(1), 57-79.

Heron, J. \& Reason, P. (2008). In: Reason, P. and Bradbury, H. (eds.), Handbook of action research. London: Sage Publications. Retrieved from:

http://www.human-inquiry.com/EECI.htm

Hitchcock, L. I. \& Battista, A. (2013). Social media for professional practice: Integrating Twitter with social work pedagogy. The Journal of Baccalaureate Social Work, 18, 33-45.

Jackson, C.A. (2016). Framing sex worker rights: How US sex worker rights activists perceive and respond to mainstream anti-sex trafficking advocacy. Sociological Perspectives, $59(1), 27-45$.

Jeffrey, L. A. \& MacDonald, G. (2006). Sex workers in the Maritimes talk back. Vancouver: UBC Press.

Keep, M. (November 30, 2015). Sex workers sexual assaults, social media, and hope. St. John's Status of Women Council. Retrieved from: https://sjwomenscentre.ca/category/shop/

Lovejoy, K., Waters, R. D. \& Saxton, G.D. (2012). Engaging stakeholders through Twitter: How nonprofit organizations are getting more out of 140 characters or less. Public Relations Review, 38(2), 313-318.

MacDonald, G., Jeffrey, L. A., Martin, K. \& Ross, R. (2013). In: van der Meulen, E., Durisin E. M. and Love, V. (eds.), Selling sex: Experience, advocacy and research on sex work in Canada. Vancouver: UBC Press, pp. 165-197.

Cultural and Pedagogical Inquiry, Summer 2018, 10(1), pp. 49-61

ISSN 1916-3460 (C) 2018 University of Alberta

http://ejournals.library.ualberta.ca/index.php/cpi/index 
Megele, C. (2014). Theorizing Twitter chat. Journal of Perspectives in Applied Academic Practice, (2)2, 46-51.

Obar, J. A. (2014). Canadian advocacy 2.0: An analysis if social media adoption and perceived affordances by advocacy groups looking to advance activism in Canada. Canadian Journal of Communication, 39, 211-233.

Safe Harbour Outreach Program (February 26, 2016) Red alert - SHOP issues a red alert in the St. John's area. St. John's Status of Women Council. Retrieved from: https://sjwomenscentre.ca/category/shop/

Safe Harbour Outreach Program (October 20, 2017). For immediate release: Turn off the spotlight: sex workers and allies urge an end to Operation Northern Spotlight. St. John's Status of Women Council. Retrieved from: https://sjwomenscentre.ca/category/shop/

Sitter, K. C. \& Curnew, A. H. (2016). The application of social media in social work community practice. Social Work Education: The International Journal, 35(3), 271-283.

Vartabedian, J. (2017). Bodies and desires on the internet: An approach to trans women sex workers' websites. Sexualities, 0(0), 1-20.

Wahab, S. (2004). Tricks of the trade: What social workers can learn about female sex workers through dialogue. Qualitative Social Work, 3(2), 139-160.

\section{Acknowledgements:}

The authors would like to acknowledge the reviewers for their thoughtful feedback. The authors would also like to acknowledge Safe Harbour Outreach Project (SHOP) for their support. 